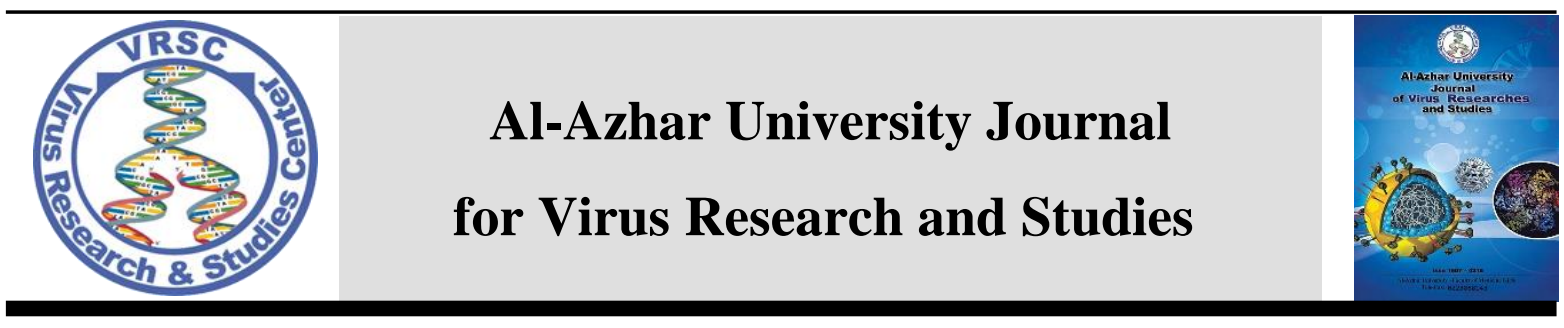

\title{
Doxycycline and Minocycline Drugs as a Treatment Proposal for Inhibition of ARDS and Inflammatory Cytokines of SARS-CoV-2
}

\author{
Mohamed A. Mostafa* \\ Faculty of Pharmacy, Mansoura University, Dakahleya \\ E-mail: sahhaa@hotmail.com
}

\begin{abstract}
The novel coronavirus 2 (COVID 19) is a highly transmittable viral disease aroused in Wuhan, China at the end of 2019 and spreads round the world. The International Committee on Taxonomy of Viruses (ICTV) named it on February 11, 2020, as severe acute respiratory syndrome Coronavirus 2 (SARS-CoV-2). SARS-CoV-2 can infect humans as well likewise as animals and transmit from person to person. The World Health Organization declared that the novel coronavirus 2 pneumonia epidemic and was classified as a public health emergency of international attention on January 30, 2020. When COVID-19 infects the upper and lower respiratory tract it can give rise to mild or acute respiratory syndrome with resultant release of cytokines like IL-1B, IL6, IL37, TNF alpha and CCL2. we evaluated the effectiveness of doxycycline and minocycline as a tetracycline derivative to modulate serum levels of cytokines and we stand out their anti- inflammatory effect that can inhibit inflammation and proinflammation response that were caused by COVID-19, providing pertinent strategy.
\end{abstract}

Keywords: COVID-19, SARS-CoV-2, ARDS, Tetracyclines, Cytokines.

\section{Introduction}

Tetracyclines are bacteriostatic antibiotics. Tetracycline mode of action based on their binding to bacterial 30s ribosomal subunit and inhibition of protein synthesis. The second generation, Doxycycline, and Minocycline are a semi-synthetic tetracycline derivative. They are better in pharmacokinetic activity than tetracyclines of the first-generation; they are totally absorbed when taken orally. Because of their high lipophilic properties, particularly Minocycline that passes through the bloodbrain barrier, both CSF and CNS cells accumulate [1]. Doxycycline has been found to support multiple sclerosis patients ,Huntington's disease and potentially rheumatoid arthritis by suppressing microglia activity [2, 3]. This, in turn, decreased the levels of several pro inflammatory cytokines including tissue necrosis factor (TNF) and interleukin 1 beta (IL-1 $\beta)$.[3 2] Doxycycline 's efficacy was studied by J. E. Z. Castro, et al.,[4] Denguetriggered cytokine control and serum regulation levels of IL-6, IL-1B, and TNF and cytokine receptor/receptor antagonists 
TNF-R1 and IL-1RA in hospitalized patients with Dengue virus disease. Minocycline's antiviral activity has been described initially against HIV [5], the infection in which $\mathrm{CD} 4+\mathrm{T}$ cells showed increased amounts of IL-1, IL-6, TNF alpha, interferon-gamma and low levels of IL-2 levels [6]. And this behavior against certain viral infections was later experimentally estimated in theSimian Immunodeficiency Virus ( SIV), Japanese Encephalitis Virus (JEV), Human Tlymphocytic virus type-1 (HTLV-1), West Nile Virus (WNV), Rabies, Sindbis, and Reoviruses.

\section{Discussion}

High cytokine levels are a hallmark of numerous bacterial and viral infectious diseases, including COVID 19 Proinflammatory cytokines, such as IL6, IL1 $\beta$, and TNF, which are thought to cause most symptoms, such as fever, malaise, and viral infection-related coagulopathies [7, 8, 9]. Indeed, the degree of imbalance between such cytokines and their Anti-inflammatory counterparts may be the disease outcome 's primary prognostic indicator.[11,10] These findings have led to the development of a wide spectrum of potential therapeutic agents, including monoclonal antibodies and antibiotics, that act to down-regulate different cytokines.[13,12] Drugs belonging to the antibiotic tetracycline class have many benefits including a long history of safe use and low cost, such as doxycycline and minocycline. They can also quickly cross the blood-brain barrier, may support the treatment of diseases within the central nervous system. In this study, we are investigating the effectiveness of doxycycline and minocycline in modulating the levels of various cytokines and soluble receptor/receptor antagonists in COVID-19 patients. Previously reported that infection with the dengue virus resulted in a marked rise in serum cytokine and cytokine receptor/antagonist levels [14,15]. Doxycycline has been known to modulate levels of proinflammatory cytokines. Rapid downregulation was observed within 3 days of diagnosis and continued into day 7 [16]. A similar effect was noted for modulated concentration of TNF R1 inhibits tissue culture multiplication and was able to interact with the dengue virus $\mathrm{E}$ protein showing effective immune-modulator and long plasma half-life [17]. On the other hand, minocycline binds to and inhibits HIV integrase, and was shown an anti-HIV activity in human CD4+ T cells resulting in a reduction in single cycle replication and reactivation, and this was the primary time that minocycline was shown to own a capability to decrease viral expression from resting CD4+ T cells .[18]

Minocycline anti-inflammatory properties since it down- regulates CD40L on T cells through the CD40/40L pathway, [19] antiapoptotic action, and immune-modulatory activity [20], and neuroprotective effects [21]. Such properties do not depend on antimicrobial activity of minocycline due to its ability to inactivate enzymes such as caspase- 1 and -3 , and to activate BcL-2 [22, 23]. The same investigators have shown that minocycline has decreased cytokine secretion such as IL-1, IL-6, and TNF- $\alpha$ resulting in cytokine storm inhibition or reduction [24]. Minocycline's neuroprotective role may be attributed to several potential modes of action involving anti-inflammatory activities, and also attributed to the inhibition of p38MAPK stimulation in microglia and therefore alleviated cytokines and chemokines release [[25], [26], [27]], anti-apoptosis [28] by preventing the release of cytochrome $\mathrm{C}$ and caspase expression.[29] As Mahyar Etminan [30] mentioned in his letter of research, based on his evidence that 
tetracyclines (doxycycline or minocycline) may be effective agents in COVID-19 treatment. As described earlier, doxycycline and minocycline are highly lipophilic antibiotics on matrix metalloproteinases (MMPs) that chelate zinc substances [31]. Coronaviruses rely on host MMPs for survival, Cell adhesion, invasion of cells, and replication.[33,32]

Tetracyclines have zinc chelating properties which can also help prevent infection with COVID-19 in humans and reduce the virus's ability to replicate within host cells. Tetracyclines could also be capable of inhibiting RNA replication on positive-sense single-stranded RNA, as COVID-19 does. The study showed that doxycycline could be used to treat the dengue virus . Doxycycline also significantly inhibited serine protease from the virus under normal human temperature and fever conditions, as well as a decrease in concentration-dependent viral replication [34]. The same investigators also found that doxycycline blocked postinfection replication with the virus' reduced ability to reach the cultured cells .[34] Another research showed a 70\% reduction in retroviral load when doxycycline was used at human body temperature as a treatment for cells.[35] Tetracyclines may also have the ability to treat infection with COVID-19 through their well-known anti-inflammatory activities, including down-regulation of the NFKB pathway due to a decline in inflammatory cytokine levels such as IL $1 \beta$, TNF $\alpha$, and IL6 independent of its antibiotic mechanism [36]. Such cytokines are significantly elevated in addition to activating the pathogenesis of its infection when SARS-CoV is exposed to lung tissue .[37] By comparison, a novel publication indicated that coronaviruses induce the proliferation of mast cells inside the respiratory submucosa, and lead to the production of inflammatory agents such as histamine, protease and inflammatory cytokines like IL-1 and IL-33 [38] are Acute respiratory distress (ARDS) syndrome primary cause. Two further studies have shown that derivatives of tetracycline can induce Mast cell apoptosis and protein-kinase $\mathrm{C}$ stimulation, therefore, rising rates of inflammatory agents in circulation.[40,39] As the outer shell of COVID-19 is lipophilic and tetracyclines are lipophilic in nature, so there is high tissue penetration of tetracyclines to the lungs which Could cause viral replication inhibition in the lungs, moreover their antiinflammatory effect, tetracyclines could have an essential therapeutic role in the treatment of COVID-19. This will lead to a decrease in death due to septic shock that may be caused by complicated pneumonia or ARDS in hospitalized patients [41].

\section{Conclusion}

The present study indicates that, by modulating the cytokine cascade, inhibiting lung inflammation, and/or ARDS, doxycycline or minocycline may provide a clinical benefit in the treatment of COVID-19. Doxycycline or minocycline can be potential COVID-19 therapeutic drugs that are in plain sight hidden away. Tetracyclines are also considerably safer than other drugs used in COVID-19 treatment trials. As for example antiretroviral drugs or chloroquine derivatives.

\section{Recommendation}

We hope to recognize and investigate the potential therapeutic effectiveness of tetracyclines from international research groups and physicians, especially doxycycline and minocycline in 
COVID-19 treatment and management of inflammatory cytokines and ARDS.

\section{Acknowledgement}

I would like to express my personal gratitude to my professors of Microbiology and Immunology, and to the Department of Biochemistry at Mansoura University, Faculty of Pharmacy. Secondly, I would also like to thank my wife (Amal Ghanem) for supporting me. Thanks to all my family helped me a lot in finalizing this article within the limited time frame. In the end I like to mention that all this work is dedicated to my father and to the spirit of my mother.

\section{References}

1. Chopra I, Roberts M. Tetracycline antibiotics: mode of action, applications, molecular biology and epidemiology of bacterial resistance. Microbiol Mol Biol Rev 2001; 65:23260.

2. Tauber SC, Nau R. Immunomodulatory properties of antibiotics. Current Molecular Pharmacology. 2008;1(1): $86-79$.

3. Lai AY, Todd KG. Hypoxia-activated microglial mediators of neuronal survival are differentially regulated by tetracyclines. GLIA. 2006;53(8):809816.

4. X. Castro, J. E. Z., Vado-Solis, I., Perez-Osorio, C., \& Fredeking, T. M. (2011). Modulation of Cytokine and Cytokine Receptor/Antagonist by Treatment with Doxycycline and Tetracycline in Patients with Dengue
Fever. Clinical and Developmental Immunology, 2011, 1-5. Science China Life Sciences., 63 (3) (2020), pp. 457 460.

5. Lemaitre $\mathrm{M}$, Guetard D, Henin $\mathrm{Y}$, Montagnier L, Zerial A. Protective activity of tetracycline analogs against the cytopathic effect of the human immunodeficiency viruses in CEM cells. Res Virol 1990; 141:5-16.

6. Szeto GL, Brice AK, Yang HC, Barber SA, Siliciano RF, Clements JE. Minocycline attenuates HIV infection and reactivation by suppressing cellular activation in human CD4+ T cells. $\mathbf{J}$ Infect Dis 2010; 201:1132-40.

7. Atrasheuskaya AV, Fredeking TM, Ignatyev GM. Changes in immune parameters and their correction in human cases of tick-borne encephalitis. Clinical and Experimental Immunology 2003;131(1):148-154.

8. Bethell DB, Flobbe K, Phuong CXT, et al. Pathophysiologic and prognostic role of cytokines in dengue hemorrhagic fever. Journal of Infectious Diseases. 1998;177(3):778782.

9. Green S, Vaughn DW, Kalayanarooj S, et al. Early immune activation in acute dengue illness is related to development of plasma leakage and disease severity. Journal of Infectious Diseases. 1999;179(4):755-762.

10. Girardin E, Roux-Lombard P, Grau GE, Suter P, Gallati H, Dayer J-M. Imbalance between tumour necrosis factor-alpha and soluble TNF receptor concentrations in severe meningococcaemia Immunology. 1992;76(1):20-23. 
11. Van Dissel JT, van Langevelde $P$, Westendorp RGJ, Kwappenberg K, Frölich M. Anti-inflammatory cytokine profile and mortality in febrile patients. Lancet. 1998;351(9107):950953.

12. Dinarello CA. Anti-cytokine therapeutics and infections. Vaccine. 2003;21(2): S24-S34.

13. Clark IA, Budd AC, Alleva LM, Cowden WB. Human malarial disease: a consequence of inflammatory cytokine release. Malaria Journal. 2006; 5:85-117.

14. Bozza FA, Cruz OG, Zagne SMO, et al. Multiplex cytokine profile from dengue patients: MIP-1beta and IFN-gamma as predictive factors for severity. BMC Infectious Diseases. 2008; 8:86-93.

15. Green S, Vaughn DW, Kalayanarooj S, et al. Early immune activation in acute dengue illness is related to development of plasma leakage and disease severity. Journal of Infectious Diseases. 1999;179(4):755-762.

16. Castro, J. E. Z., Vado-Solis, I., PerezOsorio, C., \& Fredeking, T. M. (2011). Modulation of Cytokine and Cytokine Receptor/Antagonist by Treatment with Doxycycline and Tetracycline in Patients with Dengue Fever. Clinical and Developmental Immunology, 2011, $1-5$.

17. Yang JM, Chen YF, Tu YY, Yen KR, Yang YL. Combinatorial computational approaches to identify tetracycline derivatives as flavivirus inhibitors. PLoS ONE. 2007;2(5): e428-e441.

18. X.N. Tang, Q. Wang, M.A. Koike, et al., Monitoring the protective effects of minocycline treatment with radiolabeled annexin $\mathrm{V}$ in an experimental model of focal cerebral ischemia, J. Nucl. Med. 48 (11) (2007) 1822-1828.

19. Giuliani F, Hader W, Yong VW. Minocycline attenuates $\mathrm{T}$ cell and microglia activity to impair cytokine production in $\mathrm{T}$ cell-microglia interaction. $\mathrm{J}$ Leukoc Biol 2005; 78:135-43.

20. Popovic N, Schubart A, Goetz BD, Zhang SC, Linington C, Duncan ID. "Inhibition of autoimmune encephalomyelitis by a tetracycline ". Ann Neurol 2002; 51:215-23.

21. Song Y, Wei EQ, Zhang WP, Zhang L, Liu JR, Chen Z. Minocycline protects PC12 cells from ischemic-like injury and inhibits 5- lipoxygenase activation. NeuroReport 2004; 15:2181-4.

22. Chen M, Ona VO, Li M, Ferrano RJ, Fink KB, Zhu S. minocycline inhibits caspase - and caspase -3 expression and delays mortality in a transgenic mouse model of Huntington disease. Nat Med 2000; 6:797-801.

23. Domerq M, Matute C. Neuroprotection of by tetracyclines. Trends Pharmacol Sci 2004; 25:609-12.

24. Szeto GL, Brice AK, Yang HC, Barber SA, Siliciano RF, Clements JE. Minocycline attenuates HIV infection and reactivation by suppressing cellular activation in human CD4+ $\mathrm{T}$ cells. $\mathrm{J}$ Infect Dis 2010; 201:1132-40.

25. J. Yrjänheikki, T. Tikka, R. Keinänen, G. Goldsteins, P.H. Chan, J. Koistinaho, Atetracycline derivative, minocycline, reduces inflammation and 
protects againstfocal cerebral ischemia with a wide therapeutic window, Proc. Natl. Acad. Sci. U. S.A. 96 (23) (1999) 13496-13500.

26. K. Hayakawa, K. Mishima, M. Nozako, et al., Delayed treatment with minocyclineameliorates neurologic impairment through activated microglia expressing a high-mobility group box 1inhibiting mechanism, Stroke 39 (3) (2008) 951-958.

27. T. Tikka, B.L. Fiebich, G. Goldsteins, R. Keinanen, J. Koistinaho, Minocycline, atetracycline derivative, is neuroprotective against excitotoxicity by inhibiting ac-tivation and proliferation of microglia, $\mathrm{J}$. Neurosci. 21 (8) (2001) 2580-2588.

28. X.N. Tang, Q. Wang, M.A. Koike, et al., Monitoring the protective effects of mino-cycline treatment with radiolabeled annexin $\mathrm{V}$ in an experimental model of focalcerebral ischemia, J. Nucl. Med. 48 (11) (2007) 1822-1828.

29. R.O. Sanchez Mejia, V.O. Ona, M. Li, R.M. Friedlander, Minocycline reduces trau-matic brain injury-mediated caspase-1 activation, tissue damage, and neurologicaldysfunction, Neurosurgery 48 (6) (2001) 13931399.

30. Mohit Sodhi and Mahyar Etminan, Letter to the Editor, Therapeutic Potential for Tetracyclines in the Treatment of COVID-19.

31. Zakeri B, Wright GD. Chemical biology of tetracycline antibiotics. Biochem Cell Biol. 2008;86(2):124136.
32. Humar, A., McGilvray, I., Phillips, M.J. and Levy, G.A. (2004), Severe acute respiratory syndrome and the liver. Hepatology, 39: 291-294.

33. Phillips JM, Gallagher T, Weiss SR. Neurovirulent Murine Coronavirus JHM.SD Uses Cellular Zinc Metalloproteases for Virus Entry and Cell-Cell Fusion. J Virol. 2017;91(8): e01564-16

34. Rothan HA, Mohamed Z, Paydar M, Rahman NA, Yusof R. Inhibitory effect of doxycycline against dengue virus replication in vitro. Arch Virol. 2014; 159(4):711-718.

35. Sturtz FG. Antimurine retroviral effect of doxycycline. Methods Find Exp Clin Pharmacol. 1998; 20(8):643-647.

36. Henehan M, Montuno M, De Benedetto A. Doxycycline as an antiinflammatory agent: updates in dermatology. J Eur Acad Dermatol Venereol. 2017; 31(11):1800-1808.

37. Yoshikawa T, Hill T, Li K, Peters CJ, Tseng CT. Severe acute respiratory syndrome (SARS) coronavirus-induced lung epithelial cytokines exacerbate SARS pathogenesis by modulating intrinsic functions of monocyte-derived macrophages and dendritic cells. J Virol. 2009; 83(7):3039-3048.

38. Kritas SK, Ronconi G, Caraffa A, Gallenga CE, Ross R, Conti P. Mast cells contribute to coronavirus-induced inflammation: new anti-inflammatory strategy [published online ahead of print, 2020 Feb 4]. J Biol Regul Homeost Agents. 2020; 34(1):10.23812/20- Editorial-Kritas. 
39. Sandler C, Nurmi K, Lindstedt KA, et al. Chemically modified tetracyclines induce apoptosis in cultured mast cells. Int Immunopharmacol. 2005;5(11):1611-1621.

40. Sandler C, Ekokoski E, Lindstedt KA, et al. Chemically modified tetracycline (CMT)-3 inhibits histamine release and cytokine production in mast cells: possible involvement of protein kinase C. Inflamm Res. 2005;54(7):304-312

41. Griffin MO, Fricovsky E, Ceballos G, Villarreal F. Tetracyclines: a pleitropic family of compounds with promising therapeutic properties. Review of the literature. Am J Physiol Cell Physiol. 2010;299(3):C539-C548 